\title{
The Problems of the Dream in Mexico
}

\author{
Gabriel Miranda Nava* \\ Military medical specialist in neurology, neurophysiology and sleep diseases, Mexico
}

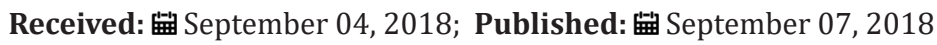

*Corresponding author: Gabriel Miranda Nava, Military medical specialist in neurology, neurophysiology and sleep diseases, Mexico

\section{Opinion}

As we discussed in our previous talk, we will talk in general about sleep disorders in our country. Fifty years ago, the first national studies began to learn about the dream and its suffering, all this thanks to clinical, neurophysiological and neuropsychological studies to understand the stages of sleep, which helped in turn to understand some statistics in general as is the fact that one third of Mexicans are snorers, which is probably increasing due to the concomitant problem of weight, and it is also known that these snoring patients have moderate to severe apneas, just under $10 \%$, or the fact that that when sleeping badly increases the prevalence of depression and anxiety in the population and at the same time its treatment becomes increasingly difficult.

a) Will you know?

b) Friend reader about the scope of this that I explain?

c) Do you know someone who does not sleep properly or who constantly complains about not sleeping well?

d) Do you have a child or nephew who has a deficit of attention due to poor sleep habits?

e) An acquaintance with mental health problems such as depression, anxiety, impulsiveness, neurosis or frantic behavior, even leading to unfinished suicidal acts?
Well, many answers are found in sleep problems. From the aforementioned sleep investigations, it has been possible to carry out a classification of sleep disorders, in order to better understand which problem corresponds to each one and adopt a clinical attitude in which a "custom-made suit" is placed the needs of each patient. This is best explained because people in common mention the word insomnia to any situation that put him in a "sleep unsatisfied" or that leads to excessive daytime sleepiness, a basic symptom that we must understand and that is understood as the presence of sleep abnormal during the daytime stage. But no, this is not the case, each condition has a name, a surname and is guided by a specific treatment and different measurements. Because friends, not everyone is treated with Diazepam or Rivotril, or antidepressants, or with valerian tea, or melatonin, nor with Dalai, no sir, each person deserves a specific treatment: there are people like snorers who deserve strict control of weight, revision by a doctor specialized in ears, nose and throat, or even some device of nocturnal oxygenation; there are the patients who are watchmen, night workers, doctors who deserve another type of control of schedules and luminous stimuli; they are also found, and really the most common, those who have bad sleeping habits, and only the fact of adhering to sleep hygiene measures is enough and enough for their improvement, in order to talk. Here, therefore, I am commenting on the international classification of sleep disorders, updated in the year of 2005 and that we will be mentioned with a brief breakdown of each one.

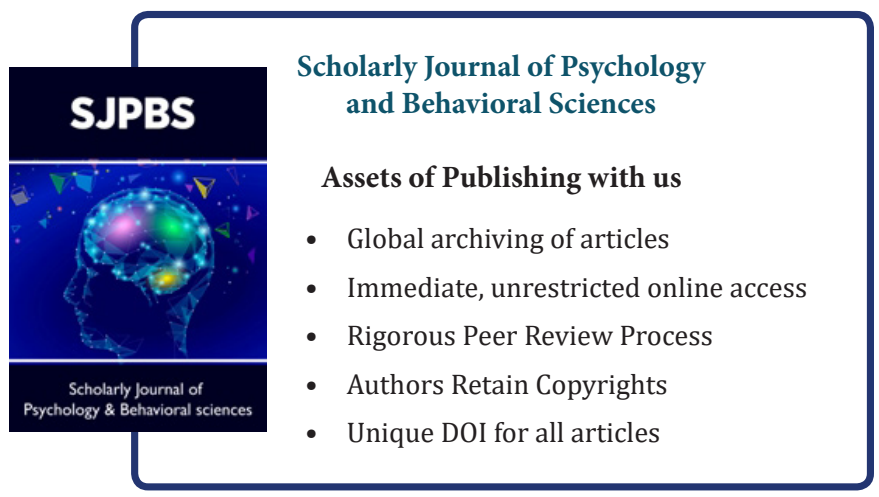

